
THE INFLUENCE OF OCCUPATIONAL RISK FACTORS

Svetlana V. Kuzmina -ORCID 0000-0002-7330-1213, Nikita D. Kuzmin, GBOU VPO «Kazan State Medical University» Russian Ministry of Health, 420012, Kazan, Butlerova str., 49. Department of Psychiatry, e-mail:

skouzmina21@list.ru

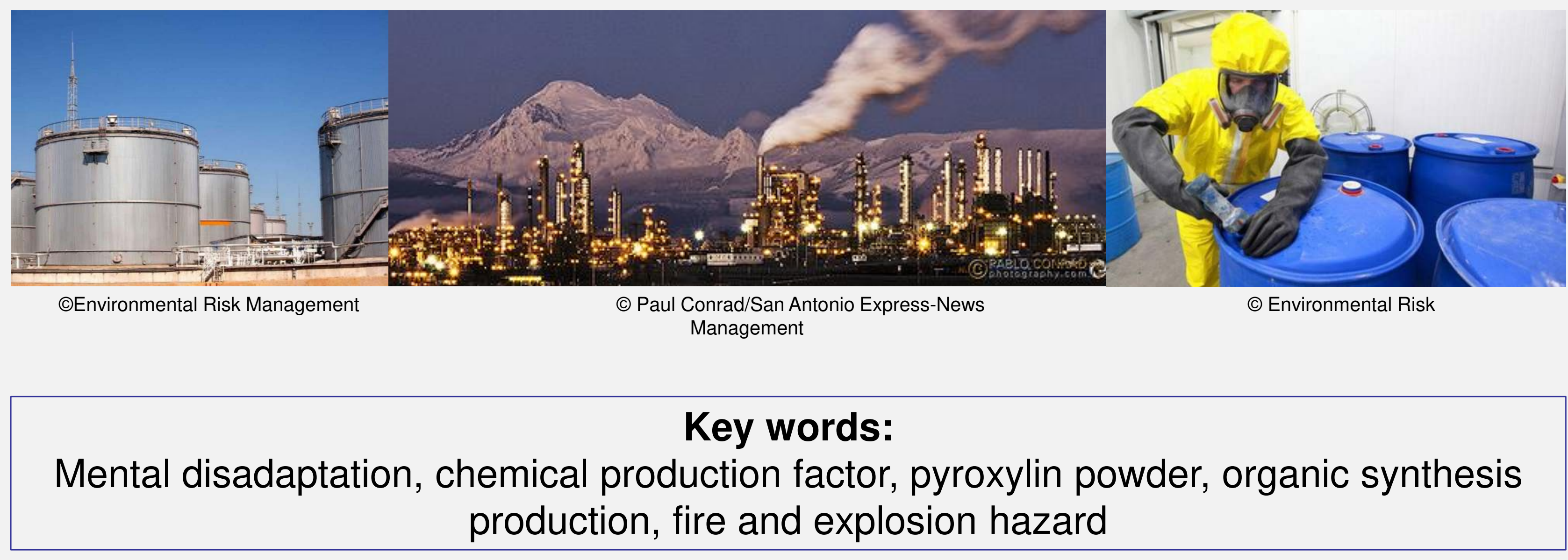

\title{
Background and Aims:
}

Industrial factors is included in the definition of "environmental health" and could play the important role in mental health of workers. In industrialized countries, 30-50\% of workers are under psychological stress, overload, which contributes to the development of mental and psychosomatic disorders (WHO, 1996). About $90 \%$ of people with symptoms of borderline mental disorder do not receive adequate medical service when they are out of sight of specialists. Evaluation of occupational environment in pyroxylin powder industry and its influence into mental health of workers - is the arm of investigation.

\section{Methods:}

Hygienic assessment of the main occupational factors - chemical, physical, the severity and intensity of the work processes, especially risk conditions for fire and explosion at the working place. Mental health examination was carried out for 95 workers during periodical medical examination on the mentioned conditions. Experience in the profession, psycho-hygienic assessment of occupational factors and personality features of workers were especially take into consideration.

Influence of combination of occupational physical and volatile solvents of organic solutions (vapors of ethyl alcohol, diethyl ether, diphenylamine, acetic acid), constant emotional stress into workers physical and mental health were studied.

\section{Results:}

Maximum allowable concentration (MAC) of vapors of ethyl alcohol annually was exceed in 3 times, MAC of vapors of diethyl ether annually was exceed in 10 times, MAC of vapors of diphenylamine and acetic acid annually was exceed in 1,5-1,75 times. The combination of chemical agents were under MACs from 1,9 to 13 times. During medical examination of workers level of occupational disorder are depended of professional experience and increasing among workers with 6 and more working years. In the structure of disadaptation - depression (16\%), conversation (16\%) and vegetative $(14,9 \%)$ symptoms were predominant among people with psychiatry symptoms. Also combination of anxiety $(3,2 \%)$, asthenia $(4,3 \%)$ and obsession $(6,4 \%)$ symptoms were investigated.

\section{Conclusions:}

Mental health differences are specifically depended of the characteristic of working conditions, especially among chemical industry. Group of workers had nonspecific mental syndromes which is not included into DSM-IV. They depend of occupational conditions: long professional experience, general patterns of staged of mental health symptoms, common clinical signs, typical for occupational conditions. 